\title{
Effects of rehabilitation on chest wall volume regulation during exercise in COPD patients
}

\author{
O. Georgiadou*, I. Vogiatzis*,\#, G. Stratakos*, A. Koutsoukou*, S. Golemati*, \\ A. Aliverti ${ }^{\star}$, C. Roussos* and S. Zakynthinos*
}

ABSTRACT: In order to investigate underlying mechanisms, the present authors studied the effect of pulmonary rehabilitation on the regulation of total chest wall and compartmental (ribcage, abdominal) volumes during exercise in patients with chronic obstructive pulmonary disease.

In total, 20 patients (forced expiratory volume in one second, mean \pm SEM $39 \pm 3 \%$ predicted) undertook high-intensity exercise 3 days $\cdot$ week $^{-1}$ for 12 weeks. Before and after rehabilitation, the changes in chest wall (cw) volumes at the end of expiration (EEV) and inspiration (EIV) were computed by optoelectronic plethysmography during incremental exercise to the limit of tolerance (Wpeak).

Rehabilitation significantly improved Wpeak (57 \pm 7 versus $47 \pm 5 \mathrm{~W}$ ). In the post-rehabilitation period and at identical work rates, significant reductions were observed in minute ventilation $\left(35.1 \pm 2.7\right.$ versus $\left.38.4 \pm 2.7 \mathrm{~L} \cdot \mathrm{min}^{-1}\right)$, breathing frequency $\left(26 \pm 1\right.$ versus $29 \pm 1$ breaths $\left.\mathrm{min}^{-1}\right)$ and EEV significantly increased (by $148 \pm 70 \mathrm{~mL}$ ). Volume reductions were attributed to significant changes in abdominal EEV and EIV (by $163 \pm 59$ and $125 \pm 27 \mathrm{~mL}$, respectively). The improvement in Wpeak was similar in patients who progressively hyperinflated during exercise and those who did not (24 and $26 \%$, respectively).

In conclusion, pulmonary rehabilitation lowers chest wall volumes during exercise by decreasing the abdominal volumes. The improvement in exercise capacity following rehabilitation is independent of the pattern of exercise-induced dynamic hyperinflation.

KEYWORDS: Chronic obstructive pulmonary disease, operational volumes, pulmonary rehabilitation

$\mathbf{T}$ herapeutic interventions, such as the use of bronchodilators [1, 2], oxygen supplementation [3, 4], lung transplantation [5] and lung volume reduction surgery $[6,7]$, have been documented to increase exercise tolerance in patients with chronic obstructive pulmonary disease (COPD) by reducing operational lung volumes during sub-maximal exercise. Furthermore, exercise training in COPD has also been shown to enhance exercise performance by reducing the ventilatory drive and respiratory discomfort at a given level of exercise [8]. Recently, PORSZASZ et al. [9] showed that enhanced exercise tolerance after rehabilitation was mediated by the improved dynamic hyperinflation, only in part, because a significant number of patients improved exercise capacity without reducing end-expiratory dynamic hyperinflation. Similarly, PUENTE-MAEsTU et al. [10] reported that the reduction in endexpiratory lung volume accounted for $50 \%$ of the improvement in exercise tolerance in patients with severe COPD. These findings were attributed to the suggestion that, besides the improved dynamic hyperinflation, other factors might contribute to the enhanced exercise tolerance after rehabilitation $[9,10]$. Such factors may involve the reduction of the mechanical restriction on tidal volume $(V \mathrm{~T})$ expansion, an improved cardiac output, reduced competition between respiratory and locomotor muscles for the available oxygen supply and locomotor muscle reconditioning [9-11].

In addition, it is known that not all patients with COPD progressively hyperinflate during exercise. There have been reports demonstrating that, besides patients who dynamically hyperinflate
AFFILIATIONS

* "M. Simou and G.P. Livanos" Laboratories, Pulmonary Rehabilitation Centre, Dept of Critical Care Medicine and Pulmonary Services, Evangelismos Hospital, and,

\#Dept of Physical Education and Sport Science, National \& Kapodistrian University of Athens, Athens, Greece.

'Dept of Bioengineering, Milan Polytechnic, Milan, Italy.

CORRESPONDENCE

I. Vogiatzis

Thorax Foundation

3 Ploutarhou Str. 10675

Athens

Greece

Fax: 302107239127

E-mail: gianvog@phed.uoa.gr

Received:

September 152006

Accepted after revision:

October 302006

SUPPORT STATEMENT

This work was supported by the European Community CARED FP5 project (contract no. QLG5-CT-20020893) and by an A. Perotti fellowship through the Thorax Foundation.

STATEMENT OF INTEREST None declared.

Online ISSN 1399-3003 
from the onset of exercise, there are also patients who either reduce end-expiratory volume (EEV) during exercise [12] or do not change EEV until they approach the maximal exercise work rate (WR), also known as late hyperinflators (LH) [13]. Therefore, exercise limitation in the latter two patient categories is not associated with end-expiratory dynamic hyperinflation and, as such, simply tracking changes in EEV during exercise is not informative of all the respiratory factors that could mediate improvements in exercise performance following an intervention. Assessment of all operational volumes is, therefore, important for understanding the respiratory mechanisms that contribute to the improved exercise capacity after rehabilitation in patients adopting different breathing strategies during exercise.

Accordingly, the main aim of the present study was to assess, by optoelectronic plethysmography (OEP), the effect of exercise training on the course of all operational chest wall volumes during exercise in patients with COPD. It is hypothesised that since exercise training is known to reduce the ventilatory requirement and the breathing frequency $(f B)$ at a given level of sub-maximal exercise [8-10], this would reduce both the chest wall end-expiratory $\left(\mathrm{EEV}_{\mathrm{cw}}\right)$ and endinspiratory volume $\left(E I V_{c w}\right)$ so that the required alveolar ventilation would be achieved at lower operating chest wall volumes. Providing that the chest wall volume at total lung capacity (TLCV $\mathrm{Cw}$ ) would not be affected by training, the adjustments in the EEV $\mathrm{cw}$ would be expected to increase the inspiratory reserve chest wall volume ( $\left(R V_{c w}\right)$, thus alleviating dyspnoea sensation and enhancing exercise tolerance. In addition, in order to better understand the potential mechanisms of improvement in chest wall volume modulation after exercise training, the effect of rehabilitation on the regulation of the ribcage and abdominal chest wall volumes was also investigated.

\section{METHODS \\ Subjects}

In total, 20 patients with clinically stable COPD met the following entry criteria: 1) post-bronchodilator forced expiratory volume in one second (FEV1) $<50 \%$ predicted and FEV1/ forced vital capacity (FVC) $<65 \%$ without significant reversibility ( $<12 \%$ change of the initial FEV1 value); 2$)$ optimised medical therapy according to Global Initiative for Chronic Obstructive Lung Disease [14]; and 3) absence of other significant diseases that could contribute to exercise limitation.

\section{Study design}

Patients participated in a pulmonary rehabilitation programme consisting predominantly of exercise training. Initially, patients were assessed for pulmonary function. Thereafter, they underwent an incremental cycle exercise test to the limit of tolerance (Wpeak) prior to entering the programme. The same procedure was followed upon completion of the programme.

\section{Rehabilitation programme}

The rehabilitation programme consisted of supervised exercise training and comprised of three sessions per week over a 12week period. Patients enrolled in the rehabilitation programme performed either constant-load (initially at 60\% Wpeak for $30 \mathrm{~min} ; \mathrm{n}=10$ ) or interval (initially at $100 \% \mathrm{~W}$ peak, $30 \mathrm{~s}$ of work alternated by $30 \mathrm{~s}$ of rest for $45 \mathrm{~min}$; $\mathrm{n}=10$ ) cycling exercise on electromagnetically braked cycle ergometers (EC-1600 CatEye Ergociser; CatEye Co., Osaka, Japan) as previously described elsewhere [15-17]. The WR was increased on a weekly basis as detailed later.

\section{Pulmonary function assessment}

Spirometry, lung transfer factor for carbon monoxide (Masterlab; Jaeger, Wurzburg, Germany) and subdivisions of lung volumes by body plethysmography (Medgraphics Autolink 1085D; Medical Graphics, St Paul, MN, USA) were performed according to recommended techniques [18].

\section{Exercise testing protocol}

Prior to entering the rehabilitation programme, all patients performed an incremental test on an electromagnetically braked cycle ergometer (Ergoline 800; Sensor Medics, Anaheim, CA, USA). The test consisted of measurements during $3 \mathrm{~min}$ of rest (R), followed by $3 \mathrm{~min}$ of unloaded pedalling and a ramp increase of load (increments of 5 or $10 \mathrm{~W} \cdot \mathrm{min}^{-1}$ ) to $\mathrm{W}$ peak. During the test, flow rate at the mouth and gas exchange variables were recorded breath-by-breath (Vmax 229; Sensor Medics). Cardiac frequency ( $f C$ ) and arterial oxygen saturation measured by pulse oximetry were determined using the R-R interval from a 12-lead online ECG (Marquette Max; Marquette Hellige $\mathrm{GmbH}$, Freiburg, Germany) and a pulse oximeter (Nonin 8600; Nonin Medical, Plymouth, MN, USA), respectively. Symptom ratings were monitored every $2 \mathrm{~min}$ throughout exercise using the 1-10 Borg scale [19]. The V-slope technique was used to detect the oxygen uptake $\left(V^{\prime} \mathrm{O}_{2}\right)$ at which the anaerobic threshold (AT) occurred, whereas the change in $V^{\prime} \mathrm{O}_{2}$ as a function of WR $\left(\Delta V^{\prime} \mathrm{O}_{2} / \Delta \mathrm{WR}\right)$ was calculated as an index of aerobic work efficiency [20]. In addition, the oxygen pulse, expressing the volume of oxygen extracted by the peripheral tissues with each beat (an index of stroke volume) was calculated by dividing $V^{\prime} \mathrm{O}_{2}$ by $f \mathrm{C}[20]$.

\section{Operational chest wall volume measurements}

End-inspiratory volume (EIV) and EEV of the total chest wall and its compartments, the ribcage and the abdomen, were measured by OEP as previously described elsewhere [13, 21-23]. To ensure that $T L C V_{C w}$ remained unchanged during exercise preand post-rehabilitation, patients were asked to perform inspiratory capacity manoeuvres during rest, unloaded cycling and every $2 \mathrm{~min}$ throughout the incremental test, according to previously described methods $[23,24]$. IRV $\mathrm{cw}$ was calculated by OEP as the difference between TLCV $\mathrm{Cw}$ and EIV $\mathrm{cw}$. Reproducibility of chest wall volume variations during exercise was established in a subgroup of four patients studied on two different occasions without pulmonary rehabilitation in the interim.

\section{Statistical analysis}

Data are presented as mean \pm SEM. Two-way ANOVA with repeated measures was used to identify statistically significant differences in chest wall volumes across different time-points within and between groups, followed by the Tukey test for post hoc analyses. Baseline differences between groups concerning pulmonary function and exercise characteristics were tested by independent t-tests, whereas differences within each group in pre- and post-rehabilitation exercise characteristics were tested 


\begin{tabular}{|c|c|c|c|}
\hline \multirow[t]{2}{*}{ TABLE 1} & \multicolumn{3}{|c|}{$\begin{array}{l}\text { Demographic and post-bronchodilator data of } \\
\text { the study population and subgroups }\end{array}$} \\
\hline & COPD & EH & LH \\
\hline Subjects $n$ & 20 & 11 & 9 \\
\hline Age yrs & $64 \pm 2$ & $60 \pm 2$ & $67 \pm 3$ \\
\hline BMI $\mathbf{k g} \cdot \mathrm{m}^{-2}$ & $25.2 \pm 0.7$ & $23.7 \pm 0.6$ & $27.2 \pm 1.1^{*}$ \\
\hline FEV 1 L & $1.03 \pm 0.08$ & $0.94 \pm 0.10$ & $1.14 \pm 0.11$ \\
\hline FEV $1 \%$ pred & $39 \pm 3$ & $32 \pm 3$ & $48 \pm 4^{*}$ \\
\hline FVC L & $2.63 \pm 0.16$ & $2.62 \pm 0.27$ & $2.65 \pm 0.17$ \\
\hline FVC \% pred & $76 \pm 4$ & $68 \pm 4$ & $85 \pm 6^{*}$ \\
\hline FEV $_{1} /$ FVC $\%$ & $40 \pm 2$ & $37 \pm 3$ & $43 \pm 3$ \\
\hline FEF25-75\% L- $\mathrm{s}^{-1}$ & $0.37 \pm 0.03$ & $0.37 \pm 0.03$ & $0.38 \pm 0.06$ \\
\hline FEF $25-75 \% \%$ pred & $11 \pm 1$ & $10 \pm 1$ & $12 \pm 2$ \\
\hline$T L, \mathrm{CO} \%$ & $47 \pm 5$ & $38 \pm 4$ & $58 \pm 9^{*}$ \\
\hline TLC L & $7.71 \pm 0.33$ & $7.86 \pm 0.47$ & $7.52 \pm 0.48$ \\
\hline TLC \% pred & $123 \pm 3$ & $124 \pm 5$ & $123 \pm 3$ \\
\hline FRC L & $5.56 \pm 0.23$ & $5.85 \pm 0.31$ & $5.21 \pm 0.32^{\star}$ \\
\hline FRC $\%$ pred & $166 \pm 4$ & $173 \pm 6$ & $157 \pm 6^{*}$ \\
\hline RV L & $4.31 \pm 0.23$ & $4.63 \pm 0.31$ & $3.91 \pm 0.32^{*}$ \\
\hline RV \% pred & $202 \pm 9$ & $213 \pm 12$ & $188 \pm 12^{\star}$ \\
\hline IC L & $2.15 \pm 0.15$ & $2.00 \pm 0.18$ & $2.32 \pm 0.23^{*}$ \\
\hline IC \% pred & $74 \pm 4$ & $66 \pm 3$ & $81 \pm 5^{\star}$ \\
\hline
\end{tabular}

Data are presented as mean \pm SEM, unless otherwise stated. COPD: chronic obstructive pulmonary disease; EH: early hyperinflators; LH: late hyperinflators; BMI: body mass index; FEV1: forced expiratory volume in one second; \% pred: $\%$ predicted; FVC: forced vital capacity; FEF $25-75 \%$ : mean forced expiratory flow between 25 and $75 \%$ of FVC; $T L, C O$ : carbon monoxide lung transfer factor; TLC: total lung capacity; FRC: functional residual capacity; RV: residual volume; IC: inspiratory capacity. ${ }^{*}: \mathrm{p}<0.05$ between $\mathrm{EH}$ and $\mathrm{LH}$

by paired t-tests. Linear regression analysis was performed using the least square method. Statistical significance was set at $\mathrm{p}<0.05$.

\section{RESULTS}

\section{Baseline patient characteristics}

At baseline, patients were characterised by severe airflow limitation and moderately reduced diffusion capacity, as

\begin{tabular}{|c|c|c|}
\hline & Pre-rehabilitation & Post-rehabilitation \\
\hline WR W & $47 \pm 5$ & $57 \pm 7^{*}$ \\
\hline WR $\%$ pred & $41 \pm 4$ & $53 \pm 5^{*}$ \\
\hline Endurance time min & $7.7 \pm 0.7$ & $9.1 \pm 0.8^{\star}$ \\
\hline$V^{\prime} \mathrm{O}_{2} L \cdot \min ^{-1}$ & $0.86 \pm 0.08$ & $1.02 \pm 0.08^{*}$ \\
\hline RER & $0.96 \pm 0.03$ & $0.97 \pm 0.02$ \\
\hline fc beats $\cdot \mathrm{min}^{-1}$ & $123 \pm 5$ & $125 \pm 5$ \\
\hline AT $L \cdot \min ^{-1}$ & $0.68 \pm 0.05$ & $0.84 \pm 0.06^{\star}$ \\
\hline $\mathrm{Sp}, \mathrm{O}_{2} \%$ & $92 \pm 1$ & $91 \pm 1$ \\
\hline
\end{tabular}

Data are presented as mean \pm SEM. WR: work rate; \% pred: \% predicted; $V^{\prime} \mathrm{O}_{2}$ : oxygen uptake; RER: respiratory exchange ratio; $f \mathrm{C}$ : cardiac frequency; $\mathrm{AT}$ : anaerobic threshold; $\mathrm{Sp}, \mathrm{O}_{2}$ : arterial oxygen saturation measured by pulse oximetry. ${ }^{*}: n=20 ;{ }^{*}: p<0.05$ between pre- versus post-rehabilitation. shown in table 1. Patients were hyperinflated at rest as indicated by the increased total lung capacity, functional residual capacity and residual volume. Their exercise capacity was severely compromised (table 2). Post-rehabilitation there were no significant changes in lung function characteristics compared with measurements at baseline.

\section{Exercise training programme}

The mean intensity sustained during the two training modalities increased progressively throughout the rehabilitation programme such that weeks 4,8 and 12 corresponded to $105 \pm 13,115 \pm 13$ and $130 \pm 16 \%$ of baseline Wpeak during interval training, and to $63 \pm 3,72 \pm 5$ and $81 \pm 5 \%$ of baseline Wpeak during constant-load training, respectively. Examination of the mean training intensities $(117 \pm 15$ versus $72 \pm 5 \%$ of baseline Wpeak for interval versus constant-load training, respectively) revealed that the total amount of work sustained during the two training regimes was not significantly different.

\section{Post-rehabilitation exercise tolerance}

Following rehabilitation there were significant improvements in Wpeak $(p=0.001)$, total exercise endurance time $(p=0.001)$, peak $V^{\prime} \mathrm{O}_{2}(\mathrm{p}=0.001)$ and $\mathrm{AT}(\mathrm{p}=0.011$; table 2$)$. At an identical WR (i.e. that of peak pre-rehabilitation), there was a significant $(p=0.044)$ reduction in minute ventilation $\left(V^{\prime} E\right)$ during the post-training exercise test that was attributed to a significant $(p=0.045)$ reduction in $f B$ (table 3$)$. This allowed for a significant increase in the expiratory time $(t E ; p=0.039)$, since the inspiratory time did not change significantly $(p=0.33$; table 3). At an identical WR, post-training dyspnoea sensation was significantly $(p=0.042)$ lower compared with the pretraining exercise test (table 3 ). The magnitude of change in all the aforementioned variables was not significantly different between the two training modalities.

\section{Operational chest wall volumes}

The reproducibility of chest wall volume measurements was evaluated by testing four patients on two different occasions without rehabilitation in the interim. Close correlations were found between changes from rest $(\Delta)$ in the EIV cw, EEV cw and $I R V_{c w}$ recorded throughout all exercise stages (fig. 1). The linear regression analyses between the two measurements (i.e. first and second) provided the following equations:

$$
\begin{aligned}
& \Delta E_{\mathrm{EIV}} \mathrm{cnd}=1.112 \Delta \mathrm{EIV}_{\mathrm{cw} 1 \mathrm{st}}-0.0085(\mathrm{r}=0.97, \mathrm{p}<0.001) \\
& \Delta \mathrm{EEV}_{\mathrm{cw} 2 \mathrm{nd}}=0.983 \Delta \mathrm{EEV}_{\mathrm{cw} 1 \mathrm{st}}-0.0074(\mathrm{r}=0.93, \mathrm{p}<0.001) \\
& \Delta \mathrm{IRV}_{\mathrm{cw} 2 \mathrm{nd}}=1.188 \Delta \mathrm{IRV}_{\mathrm{cw} 1 \mathrm{st}}+0.127(\mathrm{r}=0.92, \mathrm{p}<0.001)
\end{aligned}
$$

The effect of rehabilitation on operational chest wall volumes is shown in figure 2. Changes in $E_{\mathrm{c}} \mathrm{Cw}$ and $\mathrm{EIV}_{\mathrm{cw}}$ during exercise, both expressed as differences from rest $\left(\Delta E E V_{c w}\right.$ and $\Delta \mathrm{EIV}_{\mathrm{cw}}$, respectively) were significantly lower $(\mathrm{p}=0.028$ and $\mathrm{p}=0.042$, respectively) following rehabilitation compared with those before rehabilitation (fig. 2a). TLCV $\mathrm{cw}$ during incremental exercise did not change following rehabilitation (fig. 2).

At an identical WR after rehabilitation (i.e. that of peak prerehabilitation), $\Delta \mathrm{EEV}_{\mathrm{cw}}$ decreased significantly by $182 \pm 79 \mathrm{~mL}$ $(p=0.028$; table 3$)$, as did $\Delta E V_{c w}$ by $136 \pm 37 \mathrm{~mL}(p=0.043)$. There was a significant increase $(\mathrm{p}=0.011)$ in the IRV $\mathrm{cw}_{\mathrm{c}}$ by 


\begin{tabular}{|c|c|c|}
\hline \multirow[t]{2}{*}{ TABLE 3} & \multicolumn{2}{|c|}{$\begin{array}{l}\text { Exercise data at an identical work rate (i.e. that of } \\
\text { peak pre-rehabilitation) of the study population" }\end{array}$} \\
\hline & Pre-rehabilitation & Post-rehabilitation \\
\hline$V^{\prime} E \mathrm{~L} \cdot \mathrm{min}^{-1}$ & $38.4 \pm 2.7$ & $35.1 \pm 2.7^{\star}$ \\
\hline VT L & $1.35 \pm 0.09$ & $1.31 \pm 0.09$ \\
\hline$f B$ breaths $\cdot \mathrm{min}^{-1}$ & $29 \pm 1$ & $26 \pm 1^{*}$ \\
\hline$t ı s$ & $0.91 \pm 0.06$ & $0.98 \pm 0.07$ \\
\hline tE $s$ & $1.29 \pm 0.07$ & $1.42 \pm 0.07^{\star}$ \\
\hline tтот $s$ & $2.19 \pm 0.12$ & $2.40 \pm 0.15^{\star}$ \\
\hline$\Delta \mathrm{EIVIW}_{\mathrm{cw}} \mathrm{L}$ & $1.647 \pm 0.121$ & $1.511 \pm 0.143^{*}$ \\
\hline$\Delta \mathrm{EEV}_{\mathrm{cw}} \mathrm{L}$ & $0.396 \pm 0.098$ & $0.214 \pm 0.096^{*}$ \\
\hline IRVcw L & $0.206 \pm 0.064$ & $0.354 \pm 0.115^{\star}$ \\
\hline IRV $\mathrm{cw}_{\mathrm{w}} / \mathrm{TLCV}_{\mathrm{cw}} \%$ & $9 \pm 3$ & $17 \pm 7^{\star}$ \\
\hline Dyspnoea & $3.9 \pm 0.4$ & $3.0 \pm 0.4^{*}$ \\
\hline Leg fatigue & $4.1 \pm 0.4$ & $3.1 \pm 0.4$ \\
\hline \multicolumn{3}{|c|}{ 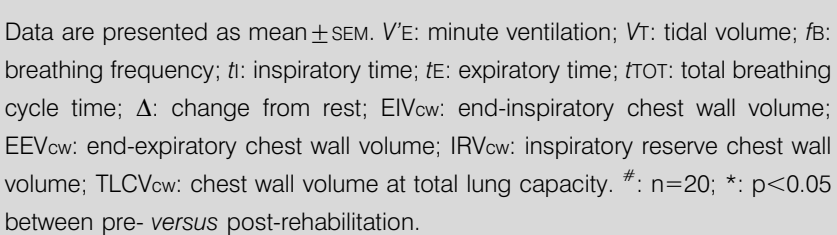 } \\
\hline
\end{tabular}

$148 \pm 70 \mathrm{~mL}$ after rehabilitation at an identical WR, which was accompanied by a significant increase in the ratio of IRVcw over the TLCV $\mathrm{cw}(\mathrm{p}=0.045$; table 3$)$. These changes in operational volumes during incremental exercise were attributed to significant reductions in mean abdominal EIV (by $125 \pm 27 \mathrm{~mL}$, $\mathrm{p}=0.020$ ) and EEV (by $163 \pm 59 \mathrm{~mL}, \mathrm{p}=0.046$; fig. 2c). Accordingly, changes in abdominal EEV and EIV were correlated to $\Delta \mathrm{EEV}_{\mathrm{cw}}(\mathrm{r}=0.92, \mathrm{p}=0.009)$ and $\Delta \mathrm{EIV}_{\mathrm{cw}}(\mathrm{r}=0.91, \mathrm{p}=0.025)$, respectively. In addition, post-rehabilitation changes in abdominal EEV and EIV for each individual subject were significantly correlated with the changes in the individual subject's exercise endurance time $(r=-0.68, p=0.006$ and $r=-0.51, p=0.041$, respectively). The ribcage compartment EIV and EEV remained unchanged after rehabilitation (fig. 2b). Operational total and compartmental chest wall volumes did not change significantly before and after rehabilitation at $W_{\text {peak }}$ (fig. 2).

\section{Patterns of dynamic hyperinflation}

Prior to rehabilitation, 11 patients were characterised by progressive development of dynamic hyperinflation $(\mathrm{EH})$, as indicated by the significant increase $(\mathrm{p}=0.026)$ in $\triangle E E \mathrm{Ev}_{\mathrm{cw}}$ from the first stage of exercise (unloaded pedalling, $0 \mathrm{~W}$ ) reaching $605 \pm 128 \mathrm{~mL}$ at $\mathrm{W}$ peak (fig. 3a); whereas the remaining patients were characterised by late development of dynamic hyperinflation (LH) as $\triangle E E V_{c w}$ was significantly increased $(\mathrm{p}=0.042$; fig. 3a) only at Wpeak by $161 \pm 78 \mathrm{~mL}$ (table 4 ).

Comparisons of the spirometric and lung volume characteristics between $\mathrm{EH}$ and $\mathrm{LH}$ revealed significantly higher absolute and predicted FEV1 and FVC (table 1), and a significantly lower degree of resting hyperinflation in $\mathrm{LH}$ compared with EH (table 1). During exercise prior to rehabilitation, Wpeak was significantly higher in the EH group even though their baseline lung function was more impaired. Furthermore, besides the aforementioned difference in
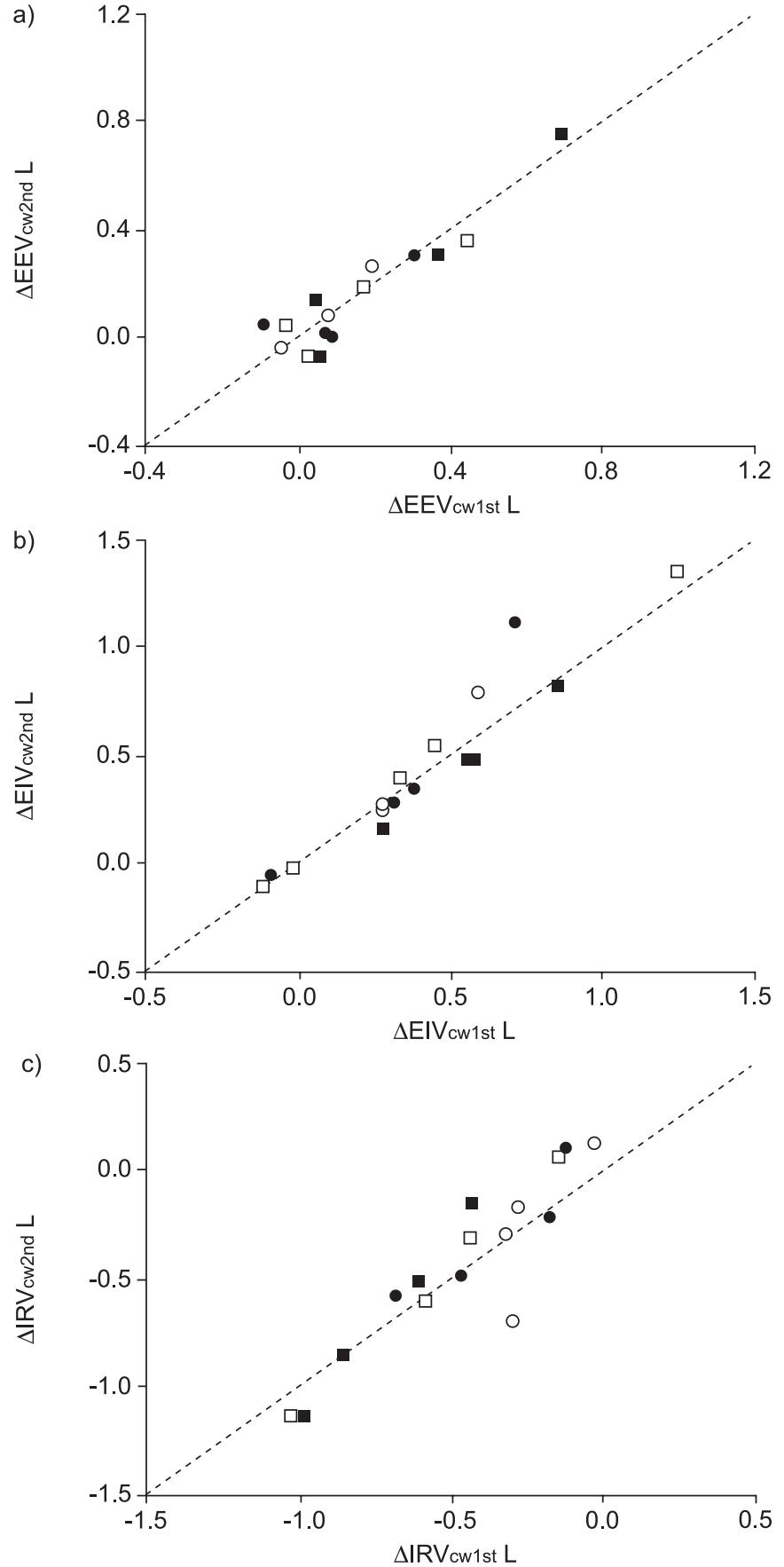

FIGURE 1. Regressions between changes from rest $(\Delta)$ in a) the endexpiratory chest wall volume $\left.\left(\Delta E E V_{c w}\right), b\right)$ the end-inspiratory chest wall volume $\left(\Delta \mathrm{EIV}_{\mathrm{cw}}\right)$ and $\left.\mathrm{c}\right)$ the inspiratory reserve chest wall volume $(\Delta \mathrm{IRV} \mathrm{cw})$ calculated by optoelectronic plethysmography during unloaded cycling $(\bigcirc)$ at $33 \%$ incremental exercise to the limit of tolerance (Wpeak; - ) at $66 \%$ Wpeak $(\square)$ and at $100 \%$ Wpeak (ם). Points were obtained from four patients studied on two occasions without rehabilitation in the interim. Line of identity (-----) is also shown.

$\Delta \mathrm{EEV}_{\mathrm{cw}}$ between the $\mathrm{EH}$ and the $\mathrm{LH}$ groups at baseline, the ratios of $\Delta V^{\prime} \mathrm{O}_{2} / \Delta \mathrm{WR}$ and that of $V^{\prime} \mathrm{E}$ in relation to the external $\mathrm{WR}$ at $\mathrm{W}$ peak, (i.e. peak $V^{\prime} \mathrm{E} /$ peak $\mathrm{WR}$ ), were significantly different between $\mathrm{EH}$ and $\mathrm{LH}$, as were $V^{\prime} \mathrm{E}, V_{\mathrm{T}}$ and $\mathrm{IRV}_{\mathrm{Cw}}$ at Wpeak prior to rehabilitation (table 4). 

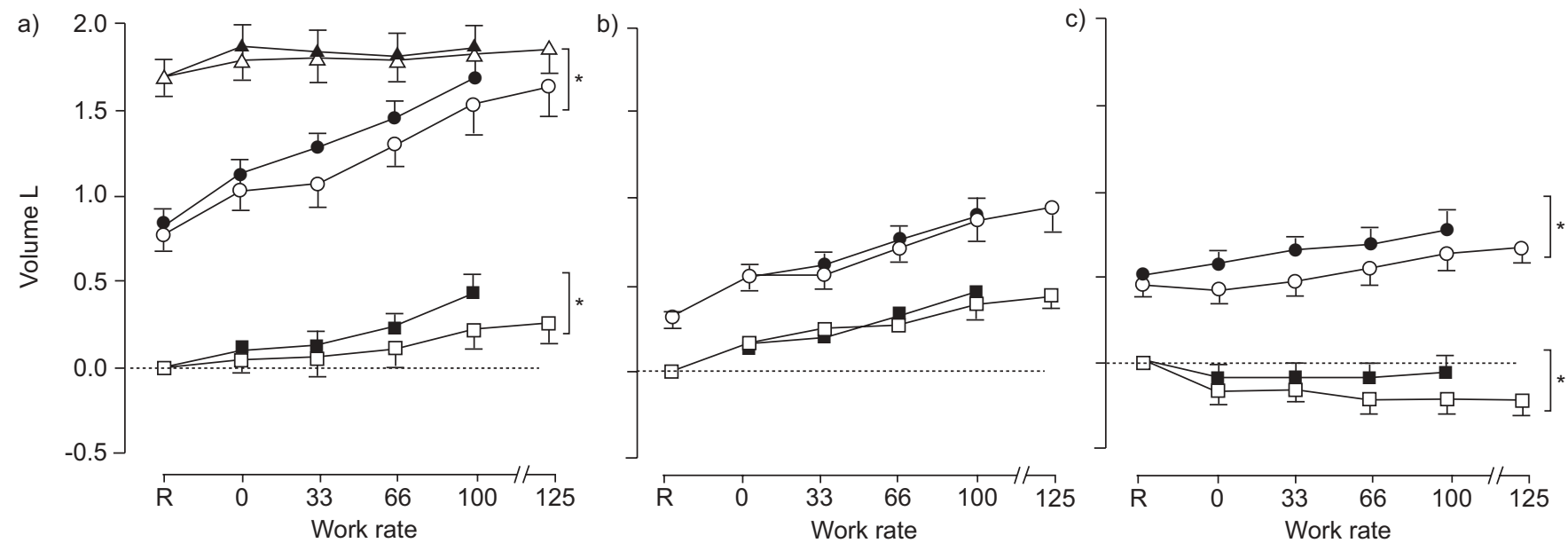

FIGURE 2. Volume changes of a) the total chest wall, b) the ribcage and c) the abdomen before ( programme during rest (R), unloaded cycling (0) and incremental exercise expressed as a percentage of peak pre-rehabilitation work rate. $\bullet$ and $\bigcirc$ : end of inspiration; and $\square$ : end of expiration; $\boldsymbol{\Lambda}$ and $\triangle$ : total chest wall volume at total lung capacity. All volumes are referred to the EEVcw at rest (----). *: $p<0.05$ between pre- and postrehabilitation.

Following rehabilitation, both EH and LH significantly improved Wpeak (by 24 and $26 \%$, respectively), peak $V^{\prime} \mathrm{O}_{2}$ (by 21 and $18 \%$, respectively), the oxygen pulse (by 18 and $17 \%$, respectively), AT (by 25\%) and the ratio of peak $V^{\prime} \mathrm{E} /$ peak WR (by 17 and $14 \%$, respectively; table 4 ). At an identical WR, both $\mathrm{EH}$ and LH significantly $(\mathrm{p}<0.05)$ reduced $V^{\prime} \mathrm{E}$ (by $3.2 \pm 1.5$ and $3.5 \pm 1.8 \mathrm{~L} \cdot \mathrm{min}^{-1}$, respectively) and dyspnoea sensation (by $1.0 \pm 0.3$ and $0.9 \pm 0.2$, respectively). As shown in table 4, $\mathrm{EH}$ and LH reached similar post-rehabilitation at Wpeak and prerehabilitation IRV and dyspnoea symptoms. The magnitude of change in these variables was not significantly different between $\mathrm{EH}$ and LH, and between interval and constant-load training modalities.

Total and compartmental chest wall volumes before and after rehabilitation in the two groups are shown in figure 3. Prior to rehabilitation $\triangle \mathrm{EEV}_{\mathrm{cw}}$ and the abdominal EEV were significantly different between $\mathrm{EH}$ and LH (fig. 3a and e). These significant differences between EH and LH persisted after rehabilitation (fig. $3 b$ and f). No differences were found in the ribcage compartmental volumes among $\mathrm{EH}$ and $\mathrm{LH}$.

\section{DISCUSSION}

The major findings of the present study are as follows: 1) rehabilitation reduced $V^{\prime} \mathrm{E}$ and $f \mathrm{~B}$ at a given level of exercise, as well as operational chest wall volumes; 2) the reductions of $\mathrm{EEV}_{\mathrm{cw}}$ and EIV $\mathrm{cw}$ were attributed to changes of the abdominal, and not the ribcage, compartment; and 3) the improvement in exercise capacity was similar in patients who progressively hyperinflated during exercise $(\mathrm{EH})$ and those who did not (LH).

In accordance with previous studies [8-10], the present rehabilitative exercise training programme induced significant improvements in peak exercise capacity, peak $V^{\prime} \mathrm{O}_{2}$ and the AT in patients with COPD. Such improvements have been shown to be independent of the exercise training modality implemented during rehabilitation [16, 17].
Similarly, in the present study both constant-load and interval exercise training were equally effective in terms of enhancing exercise tolerance. Moreover, at an identical WR there were significant reductions in the ventilatory demand, $f B$ and, hence, dyspnoea sensation. Reductions of similar magnitude in $V^{\prime} \mathrm{E}$ have also been previously reported following exercise training [8-10]. The reduced $f \mathrm{~B}$ yielded a significant increase in $t \mathrm{E}$, a response that allowed for greater lung emptying with each breath [8-10]. This adaptation after rehabilitative exercise training was shown to be associated with smaller $E E V_{c w}$ and $E I V_{c w}$ at a given level of exercise and, since $T L C V_{c w}$ remained unchanged, IRV $V_{c w}$ improved significantly, thereby yielding a considerably lower sensation of dyspnoea.

The magnitude of change in end-expiratory dynamic hyperinflation at an identical WR (by $182 \pm 79 \mathrm{~mL}$ ) after exercise training is comparable to that reported for other therapeutic interventions, including rehabilitation [1-10]. Bronchodilators [1] can lower the regulated chest wall volumes, however, retaining the same pattern of increase during exercise but shifting them towards lower operational points. Since the patients of the present study were under optimal pharmacological treatment and their resting lung function remained unchanged post-rehabilitation, improvements in chest wall volumes during exercise should be mainly attributed to the effect of rehabilitation.

The reductions in the operational chest wall volumes during exercise after rehabilitation were mainly reflected in the abdominal and not in the ribcage compartment (fig. 2). Changes in the abdominal compartment reflect changes in diaphragmatic activity [25], which has been shown to be impaired by end-expiratory dynamic hyperinflation [26]. The decrease in abdominal EEV post-rehabilitation compared with pre-rehabilitation could be the result of either increased abdominal muscle activity or the combination of prolonged $t \mathrm{E}$ with increased abdominal muscle contraction. Indeed, due to 

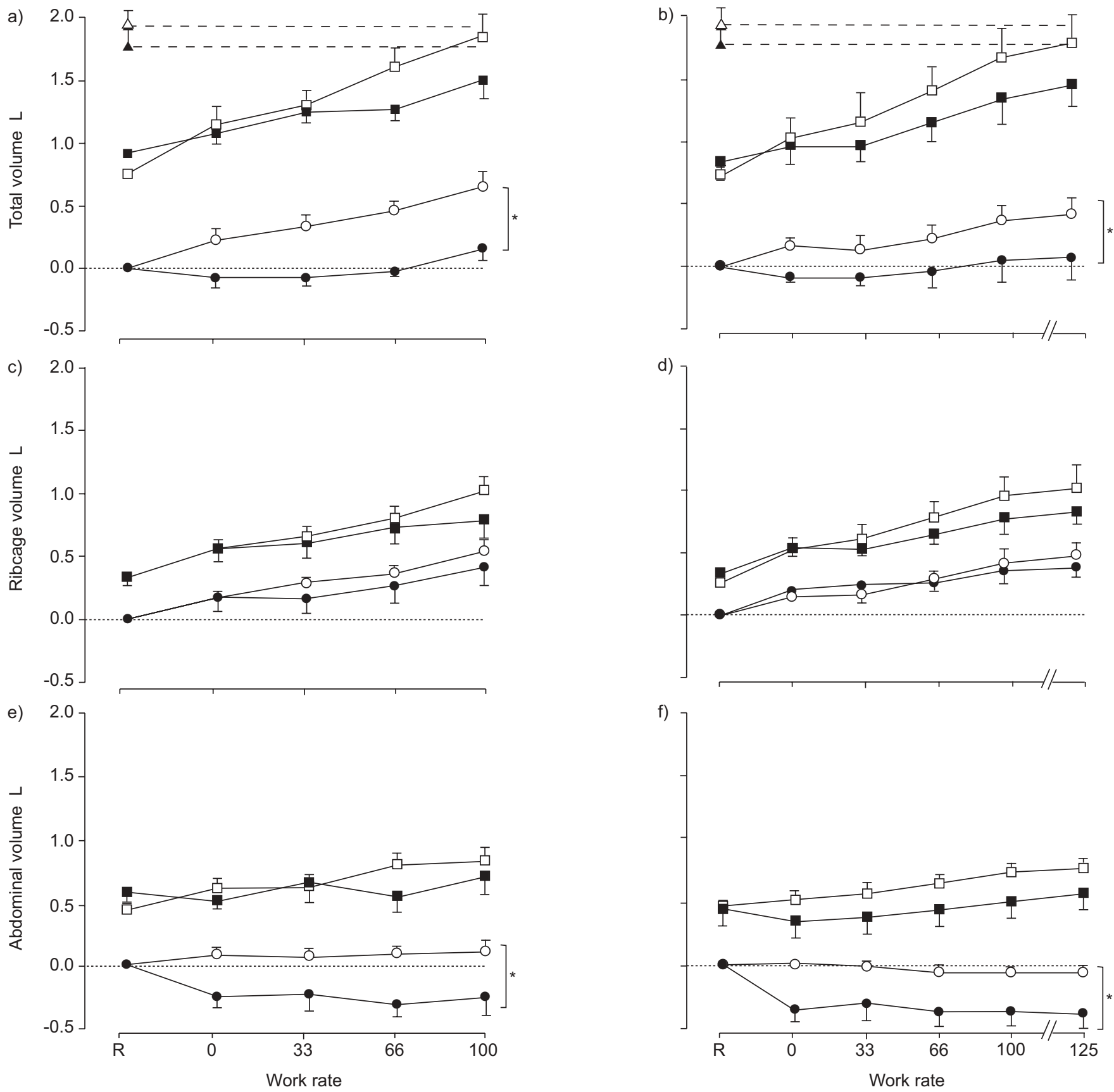

FIGURE 3. Volume changes of $a, b)$ the total chest wall, $c, d)$ the ribcage and $e, f)$ the abdomen before $(a, c, e)$ and after $(b, d$, f) the pulmonary rehabilitation programme during rest (R), unloaded cycling (0) and incremental exercise expressed as a percentage of peak pre-rehabilitation work rate in early hyperinflators (EH; $\square$ and $\bigcirc$ ) and late hyperinflators ( $\mathrm{LH} ; \boldsymbol{\square}$ and $\bullet$ ). $\square$ and $\mathbf{\square}$ : end of inspiration; $\bigcirc$ and $\bullet$ : end of expiration; $\triangle$ : total chest wall volume at total lung capacity in EH; $\mathbf{\Lambda}$ : total chest wall volume at total lung capacity in $\mathrm{LH}$. All volumes are referred to the end-expiratory chest wall volume at rest (----). ----: total chest wall volume during exercise. *: $p<0.05$ between EH and $\mathrm{LH}$.

the lower $f \mathrm{~B}, t \mathrm{E}$ was significantly prolonged post-rehabilitation at an identical WR (table 3). Abdominal muscle contraction during expiration is common at rest in COPD patients [12] and, in some cases, becomes much greater during exercise [13]. This contraction may help partition the work of breathing between the main inspiratory and expiratory muscles [27]. In healthy subjects, inward abdominal displacement during expiration stores elastic energy, which, when released, aids inspiration by allowing the diaphragm to descend [27], as could also be the case post-rehabilitation.

The present study is the first to examine the effect of rehabilitative exercise training by stratifying patients according to the pattern of EEV changes exhibited during exercise. The patients who exhibited progressive end-expiratory dynamic hyperinflation during exercise resembled those described as 
TABLE 4 Peak exercise data of the subgroups pre- and post-rehabilitation

\begin{tabular}{|c|c|c|c|c|}
\hline & \multicolumn{2}{|c|}{$\mathrm{EH}^{\#}$} & \multicolumn{2}{|c|}{$\mathbf{L H}^{\star}$} \\
\hline & Pre & Post & Pre & Post \\
\hline WR W & $50 \pm 10$ & $62 \pm 12^{*}$ & $42 \pm 6^{+}$ & $53 \pm 6^{\star,+}$ \\
\hline Endurance time min & $8.1 \pm 0.9$ & $9.8 \pm 1.2^{*}$ & $6.6 \pm 1.0^{+}$ & $8.7 \pm 1.2^{\star,+}$ \\
\hline$V^{\prime} \mathrm{O}_{2} \mathrm{~mL} \cdot \mathrm{kg}^{-1} \cdot \mathrm{min}^{-1}$ & $12.1 \pm 1.3$ & $14.7 \pm 1.8^{*}$ & $11.9 \pm 1.2$ & $14.0 \pm 1.7^{\star}$ \\
\hline AT $\mathrm{mL} \cdot \mathrm{kg}^{-1} \cdot \mathrm{min}^{-1}$ & $9.9 \pm 2.0$ & $12.3 \pm 2.9^{*}$ & $9.2 \pm 0.7$ & 11. $7 \pm 0.5^{\star}$ \\
\hline $\mathrm{O}_{2}$ pulse $\mathrm{mL} \cdot \mathrm{min}^{-1}$ & $6.5 \pm 1.5$ & $7.7 \pm 2.1^{*}$ & $7.2 \pm 1.0$ & $8.4 \pm 1.6^{*}$ \\
\hline$V^{\prime} E L \cdot \min ^{-1}$ & $35.1 \pm 4.5$ & $36.2 \pm 5.4$ & $41.3 \pm 3.1^{+}$ & $45.7 \pm 3.4^{\star,+}$ \\
\hline$V^{\prime} E / W R L \cdot \min ^{-1} \cdot W^{-1}$ & $0.70 \pm 0.14$ & $0.58 \pm 0.07^{*}$ & $0.98 \pm 0.08^{+}$ & $0.84 \pm 0.07^{*,+}$ \\
\hline$V T \mathbf{L}$ & $1.23 \pm 0.14$ & $1.39 \pm 0.16^{\star}$ & $1.45 \pm 0.12^{+}$ & $1.50 \pm 0.11^{+}$ \\
\hline$f B$ breaths $\cdot \mathrm{min}^{-1}$ & $28 \pm 2$ & $26 \pm 2^{*}$ & $29 \pm 2$ & $30 \pm 2^{+}$ \\
\hline IRV cw/TLCV $_{\text {cw }} \%$ & $5 \pm 4$ & $8 \pm 11$ & $13 \pm 5^{+}$ & $15 \pm 8^{+}$ \\
\hline Dyspnoea & $4.0 \pm 0.9$ & $4.3 \pm 0.9$ & $3.9 \pm 0.5$ & $4.0 \pm 1.0$ \\
\hline Leg fatigue & $4.0 \pm 0.7$ & $4.4 \pm 0.7$ & $4.1 \pm 0.5$ & $3.9 \pm 0.3$ \\
\hline
\end{tabular}

Data are presented as mean \pm SEM. EH: early hyperinflators; LH: late hyperinflators; WR: work rate; $V^{\prime} \mathrm{O}_{2}$ : oxygen uptake; $\Delta$ : change from rest; $\Delta V^{\prime} \mathrm{O}_{2} / \Delta W R$ : aerobic work efficiency; fC: cardiac frequency; AT: anaerobic threshold; V'E: minute ventilation; V'E/WR: ventilation to work rate ratio; $V T$ : tidal volume; fB: breathing frequency; EIV $\mathrm{Cw}^{\prime}$ : end-inspiratory chest wall volume; EEVcw: end-expiratory chest wall volume; IRVcw: inspiratory reserve chest wall volume; TLCV cw: chest wall volume at total lung capacity. ${ }^{\#}: \mathrm{n}=11 ;{ }^{\uparrow}: \mathrm{n}=9{ }^{*}{ }^{*}: \mathrm{p}<0.05$ between pre- versus post-rehabilitation; ${ }^{+}: \mathrm{p}<0.05$ between EH and LH.

EH by Vogiatzis et al. [13]. The patients who exhibited endexpiratory dynamic hyperinflation only at Wpeak, described by VoGiatZis et al. [13] as LH, also resembled to some degree those described by ALIVERTI et al. [12] in that they were able to reduce abdominal EEV throughout exercise. In the study by ALIVERTI et al. [12], as well as in the present study, the EH exhibited better exercise capacity at baseline compared with $\mathrm{LH}$, despite worse baseline lung function characteristics (tables 1 and 4). It is necessary, therefore, to recognise important differences between $\mathrm{EH}$ and LH in terms of aerobic work efficiency.

Not allowing a progressive rise in lung EEV during exercise, as in the case of $\mathrm{LH}$, has been shown to substantially increase the work of breathing in patients with COPD, mainly due to the greater recruitment of the expiratory (abdominal) muscles during expiration [12]. In addition, at Wpeak the LH had a significantly higher $V \mathrm{~T}$ and $V^{\prime} \mathrm{E}$ compared with $\mathrm{EH}$, despite similar peak $V^{\prime} \mathrm{O}_{2}$ (table 4). Hence, it is reasonable to suggest that the increase in $V^{\prime} \mathrm{O}_{2}$ by the respiratory muscles in $\mathrm{LH}$, consequent of the increase in the work of breathing, could effectively compete for a larger share of the whole body $V^{\prime} \mathrm{O}_{2}$, thereby reducing that available to leg muscles [28, 29]. Inadequate oxygen supply to meet metabolic demand of the limb muscles may play a more dominant role in limiting exercise capacity in some patients with COPD than impaired lung function or dynamic hyperinflation $[29,30]$. This may explain why the LH group exercised for less time at Wpeak (table 4), reached lower peak WR and had a higher ratio of $\Delta V^{\prime} \mathrm{O}_{2} / \Delta \mathrm{WR}$ compared with $\mathrm{EH}$.
Regardless of the pattern of end-expiratory dynamic hyperinflation, both EH and LH improved peak work capacity and maximal ability to transport and extract oxygen in the peripheral muscles during exercise to a similar degree. As such, the degree of improvement in whole body $V^{\prime} \mathrm{O}_{2}$, oxygen pulse (representing stroke volume) and AT was nearly identical between $\mathrm{EH}$ and LH (table 4), as it was the reduction in the ventilatory requirement at an identical WR during the incremental test. This finding, reported by PORSZASz et al. [9], may explain why patients who did not reduce end-expiratory dynamic hyperinflation after training still benefited from pulmonary rehabilitation.

In conclusion, the results of the present study demonstrate that rehabilitative exercise training is effective in reducing the operational chest wall volumes during exercise in patients with chronic obstructive pulmonary disease. These reductions are mainly attributed to decreases in the end-expiratory and endinspiratory volumes of the abdominal compartment, reflecting prolongation of expiratory time and possibly training-induced adaptations of the respiratory muscles. Shifting operational volumes towards a lower operating point after rehabilitation resulting in an increased inspiratory reserve volume, thus allowing exercise tolerance to be prolonged before tidal volume expansion was severely restricted. The improvement in exercise capacity following rehabilitation was independent of the pattern of end-expiratory dynamic hyperinflation during exercise, since both early and late hyperinflators improved their work and oxygen utilisation capacities to a similar degree. 


\section{REFERENCES}

1 Aliverti A, Rodger K, Dellaca RL, et al. Effect of salbutamol on lung function and chest wall volumes at rest and during exercise in COPD. Thorax 2005; 60: 916-924.

2 O'Donnell DE, Fluge T, Gerken F, et al. Effects of tiotropium on lung hyperinflation, dyspnoea and exercise tolerance in COPD. Eur Respir J 2004; 23: 832-840.

3 Somfay A, Porszasz J, Lee SM, Casaburi R. Dose-response effect of oxygen on hyperinflation and exercise endurance in nonhypoxaemic COPD patients. Eur Respir J 2001; 18: 77-84.

4 O'Donnell DE, D'Arsigny C, Webb KA. Effects of hyperoxia on ventilatory limitation during exercise in advanced chronic obstructive pulmonary disease. Am J Respir Crit Care Med 2001; 163: 892-898.

5 Murciano D, Ferretti A, Bocskowski J, Sleiman C, Fournier M, Milic-Emili J. Flow limitation and dynamic hyperinflation during exercise in COPD patients after single lung transplantation. Chest 2000; 118: 1248-1254.

6 Criner GJ, Cordova FC, Furukawa S, et al. Prospective randomized trial comparing bilateral lung volume reduction surgery to pulmonary rehabilitation in severe chronic obstructive pulmonary disease. Am J Respir Crit Care Med 1999; 160: 2018-2027.

7 Dolmage TE, Waddell TK, Maltais F, et al. The influence of lung volume reduction surgery on exercise in patients with COPD. Eur Respir J 2004; 23: 269-274.

8 Gigliotti F, Coli C, Bianchi R, et al. Exercise training improves exertional dyspnea in patients with COPD. Chest 2003; 123: 1794-1802.

9 Porszasz J, Emtner M, Goto S, Somfay A, Whipp BJ, Casaburi R. Exercise training decreases ventilatory requirements and exercise-induced hyperinflation at submaximal intensities in patients with COPD. Chest 2005; 128: 2025-2034.

10 Puente-Maestu L, Martínez Abad Y, Pedraza F, Sánchez G, Stringer WW. A controlled trial of the effects of leg training on breathing pattern and dynamic hyperinflation in severe COPD. Lung 2006; 184: 159-167.

11 Aliverti A, Macklem PT. How and why exercise is impaired in COPD. Respiration 2001; 68: 229-239.

12 Aliverti A, Stevenson N, Dellaca RL, LoMauro A, Pedotti A, Calverley PM. Regional chest wall volumes during exercise in chronic obstructive pulmonary disease. Thorax 2004; 59: 210-216.

13 Vogiatzis I, Georgiadou O, Golemati S, et al. Patterns of dynamic hyperinflation during exercise and recovery in patients with severe chronic obstructive pulmonary disease. Thorax 2005; 60: 723-729.

14 Pauwels RA, Buist AS, Ma P, Jenkins CR, Hurd SS, Gold Scientific Committee. Global strategy for the diagnoses, management, and prevention of chronic obstructive pulmonary disease. National Heart, Lung, and Blood Institute and World Health Organization Global Initiative for Chronic Obstructive Lung Disease (GOLD): executive summary. Respir Care 2001; 46: 798-825.
15 Vogiatzis I, Nanas S, Kastanakis E, Georgiadou O, Papazahou O, Roussos C. Dynamic hyperinflation and tolerance to interval exercise in patients with advanced COPD. Eur Respir J 2004; 24: 385-390.

16 Vogiatzis I, Nanas S, Roussos C. Interval training as an alternative modality to continuous exercise in patients with COPD. Eur Respir J 2002; 20: 12-19.

17 Vogiatzis I, Terzis G, Nanas S, et al. Skeletal muscle adaptations to interval training in patients with advanced COPD. Chest 2005; 128: 3838-3845.

18 Wanger J, Clausen JL, Coates A, et al. Standardisation of the measurement of lung volumes. Eur Respir J 2005; 26: 511-522.

19 Borg GA. Psychophysical bases of perceived exertion. Med Sci Sports Exerc 1982; 14: 377-381.

20 Measurements during integrative cardiopulmonary exercise testing. In: Wasserman K, Hansen JE, Sue DY, Whipp BJ, Casaburi R, eds. Principles of Exercise Testing and Interpretation. 2nd Edn. Pennsylvania, Lea and Febiger, 1994; pp. 134-146.

21 Aliverti A, Dellaca R, Pelosi P, Chiumello D, Pedotti A, Gattinoni L. Optoelectronic plethysmography in intensive care patients. Am J Respir Crit Care Med 2000; 161: 1546-1552.

22 Dellaca RL, Aliverti A, Pelosi P, et al. Estimation of endexpiratory lung volume variations by optoelectronic plethysmography. Crit Care Med 2001; 29: 1807-1811.

23 Vogiatzis I, Aliverti A, Golemati S, et al. Respiratory kinematics by optoelectronic plethysmography during exercise in men and women. Eur J Appl Physiol 2005; 93: 581-587.

24 O'Donnell DE, Webb KA. Exertional breathlessness in patients with chronic airflow limitation. The role of lung hyperinflation. Am Rev Respir Dis 1993; 148: 1351-1357.

25 Aliverti A, Iandelli I, Duranti R, et al. Respiratory muscle dynamics and control during exercise with externally imposed expiratory flow limitation. J Appl Physiol 2002; 92: 1953-1963.

26 Polkey MI, Kyroussis D, Hamnegard CH, Mills GH, Green M, Moxham J. Diaphragm strength in chronic obstructive pulmonary disease. Am J Respir Crit Care Med 1996; 154: 1310-1317.

27 Aliverti A, Cala SJ, Duranti R, et al. Human respiratory muscle actions and control during exercise. J Appl Physiol 1997; 83: 1256-1269.

28 Harms CA, Wetter TJ, McClaran SR, et al. Effects of respiratory muscle work on cardiac output and its distribution during maximal exercise. J Appl Physiol 1998; 85: 609-618.

29 Simon M, Le Blanc P, Jobin J, Desmeules M, Sullivan MJ, Maltais F. Limitation of lower limb $V^{\prime} \mathrm{O}_{2}$ during cycling exercise in COPD patients. J Appl Physiol 2001; 90: 1013-1019.

30 Montes de Oca M, Rassulo J, Celli BR. Respiratory muscle and cardiopulmonary function during exercise in very severe COPD. Am J Respir Crit Care Med 1996; 154: 1284-1289. 